\title{
Caracterização do Cordão na Soldagem FCAW com um Arame Tubular Rutílico
}

\author{
(Bead Characterization on FCAW Welding of a Rutilic Tubular Wire)
}

\author{
Cícero Murta Diniz Starling ${ }^{1}$, Paulo J. Modenesi ${ }^{2}$, Tadeu Messias Donizete Borba ${ }^{3}$ \\ ${ }^{1}$ Universidade Federal de Minas Gerais, Departamento de Engenharia de Materiais e Construção, Programa de Pós Graduação em \\ Engenharia Mecânica da UFMG, Belo Horizonte,Brasil, cicerostarling@ufmg.br \\ ${ }^{2}$ Universidade Federal de Minas Gerais, Departamento de Engenharia Metalúrgica e de Materiais, \\ Belo Horizonte, Brasil, modenesi@demet.ufmg.br \\ ${ }^{3}$ Universidade Federal de Minas Gerais, Engenheiro Metalurgista, Belo Horizonte, Brasil,tadeumdborba@yahoo.com.br
}

\begin{abstract}
Resumo
Este trabalho objetivou o estudo do efeito de algumas condições operacionais nas características do cordão produzido por um arame tubular rutílico (ASME SFA-5.20: E71T-1/E71T-9/E71T-9M) de fabricação nacional com 1,2 mm de diâmetro, destinado à soldagem de aços carbono comuns estruturais de baixo e médio teor de carbono. Realizaram-se testes de soldagem, na posição plana, sobre chapas grossas (espessura de $12 \mathrm{~mm}$ ) de aço carbono comum de baixo carbono utilizando-se uma fonte operando no modo "tensão constante" e com monitoração dos sinais de corrente e tensão do arco e velocidade de alimentação (fusão) do arame. Variaram-se a composição do gás de proteção (75\% Ar-25\% $\mathrm{CO}_{2}$ e $100 \% \mathrm{CO}_{2}$ ), a polaridade do eletrodo (positiva e negativa) e a velocidade de alimentação do arame (7 e $9 \mathrm{~m} / \mathrm{min})$. Os demais parâmetros de soldagem foram mantidos fixos, incluindo-se os comprimentos energizado do eletrodo (16 mm) e do arco (3,5 mm). Avaliaram-se os efeitos das condições operacionais nas principais características do cordão incluindo a sua geometria (penetração, reforço, largura, área fundida, área depositada e diluição), presença de descontinuidades, microestrutura e dureza. Levantaram-se, para o arame rutílico, as condições operacionais de maior produtividade (maior taxa de deposição) associadas a um cordão com características adequadas à soldagem de chapas grossas de aços estruturais.
\end{abstract}

Palavras-chave: Processo FCAW; Arame Tubular Rutílico; Formato do Cordão; Microestrutura.

Abstract: This paper studies the effect of operational conditions on bead shape characteristics in FCA welding with a Brazilian made wire with rutilic flux (ASME SFA-5.20: E71T-1/E71T-9/E71T-9M) of $1.2 \mathrm{~mm}$ diameter. Bead-on-plate downhand welding trials were performed on $12 \mathrm{~mm}$ thick low carbon steel plates with a constant voltage power supply. A digital data logging system was used to measure the welding current and voltage, and wire feed rate. While the shielding gas composition $\left(75 \% \mathrm{Ar}^{-25 \%} \mathrm{CO} \text { and } 100 \% \mathrm{CO}\right)_{2}$, wire polarity and feed rate ( 7 and $9 \mathrm{~m} / \mathrm{min})$ were varied during the trials, the electrode extension (16 mm) and arc length (3.5 mm) were not changed. Weld bead characteristics (penetration depth, width, and fused and deposited areas), the presence of discontinuities, bead microstructure and hardness were evaluated. Welding conditions of high productivity (high deposition rate) associated to adequate bead characteristics were determined for the wire.

Key-words: FCAW Process; Rutilic Tubular Wire; Weld Bead Shape; Microstructure.

\section{Introdução}

A soldagem a arco com arame tubular (FCAW) é um processo que acumula as principais vantagens da soldagem com arame maciço e proteção gasosa (GMAW), como alto fator de trabalho do soldador, alta taxa de deposição, alto rendimento, resultando em alta produtividade e qualidade da solda produzida. Inclui também as vantagens da soldagem manual com eletrodos revestidos (SMAW), como alta versatilidade, possibilidade de ajustes da composição química do cordão de solda e facilidade de operação em campo[1-2]. Na soldagem FCAW e em outros

(Recebido em 06/02/2008; Texto Final em 10/09/2009). processos de soldagem com eletrodo consumível, o material do eletrodo precisa ser aquecido desde a sua temperatura inicial, próxima da temperatura ambiente, até a sua temperatura de fusão e, a seguir, ser fundido e separado do eletrodo. A velocidade com que o eletrodo é fundido deve ser, em média, igual à velocidade que este é alimentado de forma a manter um comprimento de arco relativamente constante.

Os autores do presente trabalho estudaram anteriormente as características e os fatores determinantes da fusão de arames tubulares nacionais (destinados à soldagem de aços carbono comuns de baixo e médio teor de carbono) dos tipos básico (ASME SFA-5.20: E71T-5/E71T-5M), rutílico (ASME SFA5.20: E71T-1/E71T-9/E71T-9M) e "metal cored" (ASME SFA-5.18: E70C-3M) com 1,2 mm diâmetro, utilizando uma fonte do tipo "tensão constante" e condições de soldagem 
essencialmente sem a ocorrência de curtos-circuitos. Nesses trabalhos anteriores:

- Promoveu-se a caracterização dos arames, através da determinação das suas características geométricas e resistividade e avaliação dos principais constituintes do fluxo[3].

- Levantou-se as principais características de transferência metálica, através da técnica de perfilografia (shadowgrafia) [4].

- Avaliou-se a velocidade de fusão e a taxa de deposição dos arames em função de diferentes parâmetros operacionais, como corrente de soldagem, gás de proteção $\left(100 \% \mathrm{CO}_{2} \mathrm{e}\right.$ $75 \% \mathrm{Ar}-25 \% \mathrm{CO}_{2}$ ), comprimento energizado do eletrodo, comprimento do arco e polaridade do eletrodo [5-7] e

- Foi proposto um modelo alternativo para a fusão do eletrodo na soldagem com arames tubulares[3].

A partir da caracterização dos arames tubulares, verificouse, por exemplo, que o fluxo interno do arames rutílico, básico e "metal cored" devem ser constituídos respectivamente por grandes proporções de $\mathrm{TiO}_{2}, \mathrm{CaO}$ e adições metálicas. Às temperaturas ambiente e de fusão, as resistividades dos arames tubulares básico e rutílico são próximas. De uma forma geral, o modelo clássico para a velocidade de fusão pode descrever satisfatoriamente a fusão dos arames tubulares avaliados, apesar das suas diferenças em relação aos arames maciços. Na soldagem com "tensão constante" e o eletrodo positivo verificou-se, por exemplo, que a composição do gás de proteção e o valor do comprimento do arco não exercem um maior efeito na velocidade de fusão dos arames tubulares rutílico, básico e "metal cored". $\mathrm{O}$ arame "metal cored" apresenta velocidades de fusão mais próximas à de arames maciços. Apesar de apresentarem fluxos internos de natureza diferente, os arames rutílico e básico tiveram velocidades de fusão muito próximas para os dois gases de proteção e comprimentos energizados do eletrodo utilizados. De uma forma geral, o tipo de transferência metálica observada para os arames tubulares é globular ou globular repulsiva. Em particular, para os arames básico e rutílico verificou-se que, em muitas condições operacionais, se forma uma coluna de fluxo projetada em direção à poça de fusão. À exceção da soldagem do arame "metal cored" a altas correntes com 75\% Ar-25\%CO2, não se notou a ocorrência da transferência do tipo spray. Estes aspectos, até então estudados, foram muito importantes, tendo aplicação na determinação de condições operacionais de maior produtividade, no controle do processo e no projeto de juntas soldadas.

Encontrou-se na literatura alguns estudos relativos às características do cordão de solda (por exemplo, geometria, presença de descontinuidades e microestrutura) na soldagem com arames tubulares[8-15]. De uma forma geral, estes estudos associam as características do cordão com os parâmetros de soldagem ou com as propriedades mecânicas da junta soldada. Entretanto, percebe-se que os aspectos relativos às características do cordão de solda no processo FCAW não foram, ainda, estudados de forma mais abrangente, por exemplo, associando estas características às condições operacionais para aplicações envolvendo arames tubulares destinados à soldagem de aços carbono comuns de baixo e médio teor de carbono.
Assim, informações relativas às condições de boa estabilidade operacional e de maior produtividade (maior taxa de deposição), associadas a um cordão com características adequadas à soldagem de aços estruturais (envolvendo, boa aparência superficial, boa penetração, ausência de descontinuidades e com predominância de microconstituintes que favoreçam a resistência mecânica, aliada a uma boa tenacidade e ductilidade da solda) são, até então, limitadas.

Da mesma forma que o estudo das características e dos fatores determinantes da fusão de arames tubulares, um estudo complementar sobre o efeito das condições operacionais nas características do cordão de solda revela-se igualmente importante. Esse estudo complementar será realizado para arames tubulares nacionais destinados à soldagem de aços carbono comuns de baixo e médio teor de carbono, consistindo em uma continuidade dos trabalhos desenvolvidos anteriormente pelos autores do presente trabalho com os mesmos consumíveis. Nesse sentido, o presente trabalho tem como objetivo promover um estudo exploratório na soldagem com um arame tubular nacional do tipo rutílico (ASME SFA-5.20: E71T-1/E71T-9/ E71T-9M) sobre o efeito de algumas condições operacionais (velocidade de alimentação do arame, composição do gás de proteção e polaridade do eletrodo) na estabilidade do processo e nas características resultantes do cordão de solda (geometria, presença de descontinuidades, microestrutura e dureza). Esperase que os resultados gerados para esse arame tubular rutílico possam contribuir para a otimização de condições operacionais de maior produtividade, associadas a um cordão de solda com características adequadas à soldagem de aços estruturais.

\section{Materiais e Métodos}

Neste trabalho, utilizou-se o processo FCAW com um arame tubular comercial de fabricação nacional (destinado à soldagem de aços carbono comuns de baixo e médio teor de carbono) do tipo rutílico (ASME SFA-5.20: E71T-1/E71T-9/ E71T-9M), possuindo diâmetro nominal de 1,2 mm. Segundo o fabricante do consumível, o metal depositado pelo arame tubular resultava em $0,04 \% \mathrm{C}, 0,50 \% \mathrm{Si}$ e $1,30 \% \mathrm{Mn}$ (na soldagem com $100 \% \mathrm{CO}_{2}$ ) ou em $0,055 \% \mathrm{C}, 0,60 \% \mathrm{Si}$ e $1,50 \% \mathrm{Mn}$ (na soldagem com $\mathrm{Ar}$ e $20-25 \% \mathrm{CO}_{2}$ ). Os testes de soldagem foram realizados na posição plana por simples deposição de cordões sobre chapas de aço carbono comum (ABNT 1010, com 50x250x12 mm), utilizando-se uma fonte de soldagem operando no modo "tensão constante" e ângulo de soldagem de $90^{\circ}$. Variaram-se a velocidade de alimentação (fusão) do arame (7 e $9 \mathrm{~m} / \mathrm{min}$ ), o gás de proteção $\left(75 \% \mathrm{Ar}-25 \% \mathrm{CO}_{2}\right.$ e $\left.100 \% \mathrm{CO}_{2}\right)$ e a polaridade do eletrodo (positiva e negativa), totalizando 8 condições operacionais distintas. Realizaram-se duas ou mais soldas para cada condição operacional avaliada. No início de cada teste, o valor desejado da velocidade de alimentação do arame era ajustado através de um potenciômetro ligado ao alimentador de arame e, em seguida, promovia-se o ajuste do comprimento do arco através da variação da tensão fornecida pela fonte de soldagem. Durante os testes, a imagem invertida do arco elétrico era projetada (por meio de uma lupa) com uma ampliação conhecida sobre um anteparo graduado de forma a 
possibilitar o ajuste do seu comprimento (La) ao valor pretendido $(3,5 \mathrm{~mm})$. O valor do comprimento do arco utilizado foi o mesmo adotado pelos autores do presente trabalho em estudos anteriores utilizando-se o mesmo consumível[4-7]. Segundo os estudos anteriores, o comprimento de arco de $3,5 \mathrm{~mm}$ foi levantado a partir de condições operacionais recomendadas pelo fabricante do consumível e constatou-se que o mesmo resultava (na soldagem com ambos os gases de proteção e polaridades) em uma ampla faixa de variação da corrente de soldagem e da velocidade de alimentação do arame sem a ocorrência de transferência de metal por curto circuito.

Para que a projeção do arco não se movesse em relação ao anteparo, facilitando o ajuste do comprimento do arco, mantevese a tocha de soldagem fixa durante os testes, enquanto o corpo de prova se deslocava por intermédio de um dispositivo tipo "tartaruga". Previamente, a distância entre a peça e o bico de contato (DBCP) era fixada em 19,5 mm resultando, após o ajuste do comprimento do arco, em um comprimento energizado do eletrodo (s) igual a $16,0 \mathrm{~mm}$. De forma a se manter aproximadamente constante o volume da poça de fusão e, assim, tornar sistemática a sua influência no ajuste do comprimento do arco, foi estabelecida uma relação de proporcionalidade entre as velocidades de soldagem $\left(\mathrm{v}_{\mathrm{s}}\right)$ e de alimentação do arame (w), utilizando-se as mesmas unidades:

$$
\mathrm{v}_{\mathrm{s}}=0,04 . \mathrm{w}
$$

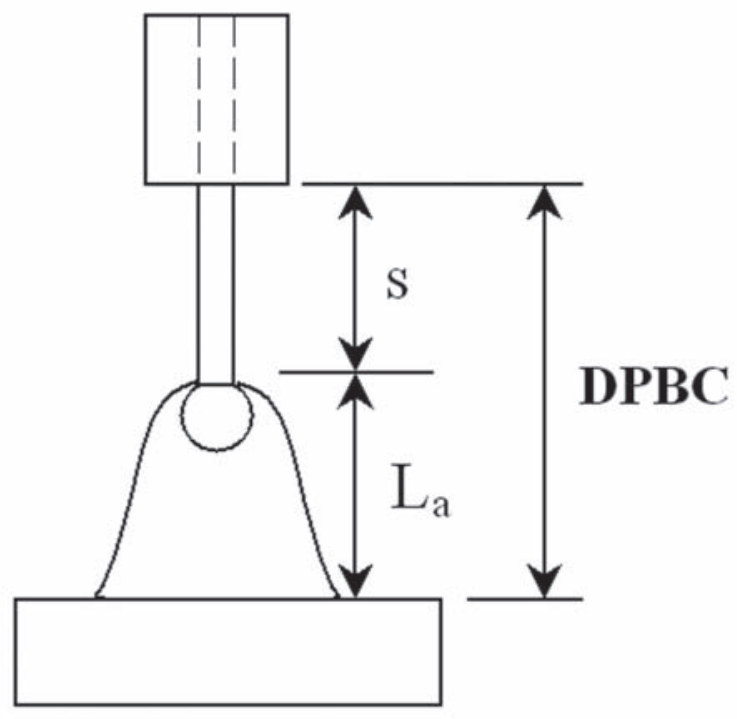

(a)
Após estes ajustes, os valores resultantes de corrente de soldagem, tensão do arco (avaliada entre o bico de contato e a peça) e velocidade de alimentação do arame eram coletados através de placas de aquisição de dados acopladas a microcomputadores. Para a aquisição da corrente, utilizou-se um sensor de efeito Hall e, para a aquisição da tensão, um sensor divisor de tensão, ambos ligados a uma placa de conversão analógico/digital controlada por um programa de computador desenvolvido previamente. Para a aquisição da velocidade de alimentação do arame, utilizou-se um sensor de disco óptico ligado a uma placa de aquisição de dados, controlada por um programa de computador específico. A Figura 1 mostra esquematicamente a montagem experimental utilizada, incluindo o sistema de projeção do arco elétrico. As aquisições da corrente de soldagem e da tensão do arco ocorreram para uma frequiência de $5000 \mathrm{~Hz}$ e para um tempo de $2 \mathrm{~s}$, sendo, por limitações do sistema, menor do que o tempo total de soldagem. A média e o desvio padrão dos valores coletados da velocidade de alimentação do arame, da corrente de soldagem e da tensão do arco foram calculados considerandose todo o tempo de aquisição. Entretanto, visando uma melhor resolução dos eventos, os oscilogramas de corrente de soldagem e tensão do arco foram construídos para um intervalo de $250 \mathrm{~ms}$ para condições típicas dos sinais.

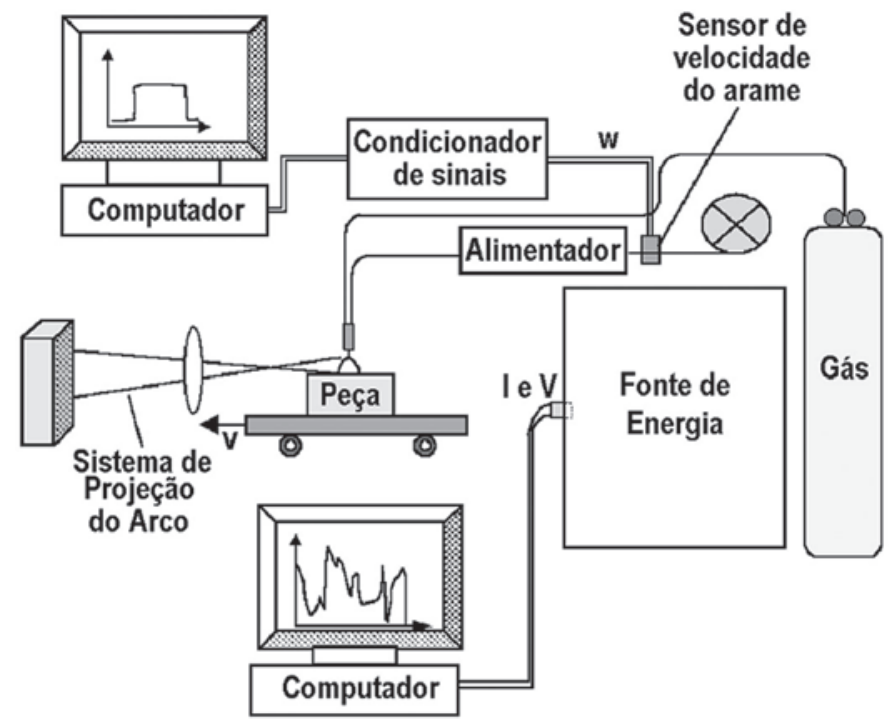

(b)

Figura 1. (a) Representação da distância entre a peça e o bico de contato (DBPC) e os comprimentos do arco (La) e energizado do eletrodo (s). (b) Representação esquemática da montagem experimental.

A caracterização de cada condição operacional foi realizada através da avaliação da estabilidade operacional, do aspecto superficial do cordão de solda, da taxa de deposição e, também, extraindo-se corpos de prova transversais ao cordão para análises macroestrutural e microestrutural e para realização de testes de dureza Vickers.

A estabilidade operacional de cada uma das condições testadas foi avaliada através das análises dos oscilogramas de tensão do arco e corrente de soldagem (em particular da relação entre o desvio padrão e a média destes parâmetros, que indicam os seus níveis de flutuação durante a operação de soldagem), do aspecto superficial do cordão, do nível de respingos produzidos e da eficiência de deposição. Para a obtenção da eficiência de deposição do arame tubular rutílico $\left(\varphi_{\text {tubular }}\right)$, inicialmente promovia-se a determinação da massa de uma chapa limpa e esmerilhada e, em seguida, depositava-se na mesma um cordão de solda utilizando-se uma das condições operacionais avaliadas. Após a soldagem, removia-se (com escova de aço giratória e 
talhadeira) todos os óxidos e respingos formados e determinava-se o ganho de massa do corpo de prova devido ao metal depositado. O consumo de arame (em metros) para a deposição do cordão era avaliado a partir da monitoração, durante a soldagem, da velocidade de alimentação do arame. Com o conhecimento da densidade linear do arame $(6,93 \mathrm{~g} / \mathrm{m})$, calculada conforme procedimento descrito em Starling e Modenesi[3], era possível determinar a massa total de arame fundido durante a soldagem. Dessa forma, a eficiência de deposição era avaliada através da relação entre o ganho de massa do corpo de prova e a massa total de arame fundido. Para cada condição operacional, avaliouse a eficiência de deposição média realizando-se pelo menos 2 soldas. A taxa de deposição $\left(\mathrm{TD}_{\text {tubular }}\right)$ do arame tubular rutílico depende da eficiência de deposição $\left(\varphi_{\text {tubular }}\right)$ e da velocidade de alimentação (w), sendo dada por:

$\mathrm{TD}_{\text {tubular }}=0,06 \cdot \varphi_{\text {tubular }} \cdot\left(\mathrm{A}_{\text {tubular }} \cdot \rho_{\text {tubular }} \cdot \mathrm{w}\right)$

Para $\mathrm{TD}_{\text {tubular }}(\mathrm{kg} / \mathrm{h})$ e $\mathrm{w}(\mathrm{m} / \mathrm{min})$. Nesta equação, $\mathrm{A}_{\text {tubular }}$ se refere à área total da seção transversal $\left(1,0679 \mathrm{~mm}^{2}\right)$ e $\rho_{\text {tubular }}$ à densidade volumétrica $\left(6,48 \mathrm{~g} / \mathrm{cm}^{3}\right)$ do arame tubular rutílico calculadas conforme procedimento descrito em Starling e Modenesi[3].

Prepararam-se 2 macrografias e 1 micrografia para cada uma das 8 condições operacionais avaliadas. A preparação macrográfica foi realizada em dois corpos de prova transversais a um mesmo cordão e consistiu no lixamento com lixas d'água (granulometrias iguais a 100, 240, 320, 400, 600 e 1000), seguindo-se ataque com nital $10 \%$. A preparação micrográfica foi realizada em um único corpo de prova transversal ao cordão e consistiu no seu embutimento a quente com resina termofixa (baquelite), lixamento com lixas d'água (mesmas granulometrias anteriores), polimento com pastas de diamante (com granulometria de 9,3 e $1 \mu \mathrm{m}$ ) e ataque com nital $2 \%$. Após a preparação das amostras, foram realizadas macrofotografias e microfotografias digitais da seção transversal do cordão. $\mathrm{O}$ aspecto superficial do cordão também foi documentado através de macrofotografia digital.

A partir das macrografias produzidas e, também, através do exame do aspecto superficial do cordão foi verificada a presença de eventuais descontinuidades (por exemplo, aspecto irregular do cordão, porosidades, mordeduras e inclusão de escória). As macrografias produzidas foram avaliadas em um projetor de perfil para a observação dos contornos da zona fundida e medição de alguns parâmetros geométricos (largura, penetração máxima e reforço, Figura 2). Esses contornos foram desenhados em uma transparência colocada sobre a tela do projetor, digitalizados através de um scanner e, através de um programa de computador, foram determinadas outras características geométricas do cordão (área depositada e área de penetração, Figura 2) e um parâmetro derivado (diluição). Os testes de dureza Vickers foram realizados na zona fundida de cada uma das 8 condições operacionais avaliadas. Utilizou-se uma carga de 98,1 N (10 kgf) com 10 a 15 medidas para cada condição e apresentaram-se os resultados para um intervalo de confiança de $95 \%$. Por se tratar de soldas com um único passe sobre chapa, não se esperava variações apreciáveis de dureza ao longo da zona fundida. Assim, as impressões foram realizadas aleatoriamente, tanto na região da área depositada como na região da área de penetração.

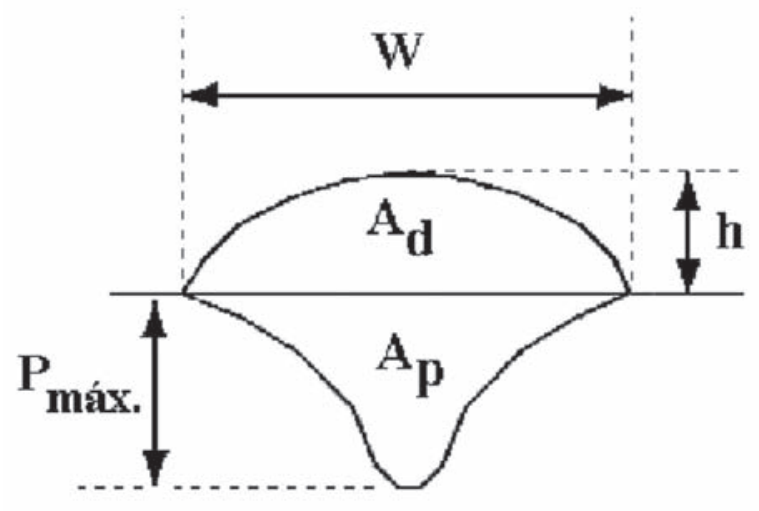

Figura 2. Representação esquemática das características geométricas do cordão. $\mathrm{W}$ - largura, $\mathrm{h}$ - reforço, $\mathrm{P}_{\max }$ -penetração máxima, $\mathrm{A}_{\mathrm{d}}$ - área depositada e $\mathrm{A}_{\mathrm{p}}$ - área de penetração.

A caracterização microestrutural foi realizada através de exames ao microscópio óptico na seção transversal dos cordões para a identificação geral dos microconstituintes presentes nazona fundida. Também foram determinadas as frações volumétricas dos microconstituintes por metalografia quantitativa. A identificação dos microconstituintes foi baseada no documento IX-1533-88 do IIW - Instituto Internacional de Soldagem[16]. As frações volumétricas dos microconstituintes foram medidas pelo método de contagem manual de pontos, segundo a norma ASTM E 562-89[17]. Utilizou-se uma malha de 25 pontos a qual foi colocada na tela de um monitor de alta resolução acoplado a um microscópio óptico. As contagens foram realizadas para um aumento fixo de $500 \mathrm{X}$ no microscópio, o qual resultava em um aumento de, aproximadamente, $1.200 \mathrm{X}$ no monitor. Calculouse um intervalo de confiança de $95 \%$ para os valores da fração volumétrica de cada microconstituinte. Para cada amostra, foram realizadas 100 aplicações da malha ao longo da zona fundida. Resultou-se, assim, na contagem de 2.500 pontos por amostra e, considerando-se as 8 condições operacionais distintas, 20.000 pontos no total. De forma a se evitar sobreposições em uma mesma região da zona fundida, as aplicações da malha ocorreram ao longo de linhas paralelas à superfície da chapa, envolvendo tanto a área depositada como a área de penetração, de forma a se cobrir homogeneamente todas as regiões da zona fundida. Assim, os resultados da metalografia quantitativa eram representativos de toda a zona fundida. Por se tratar de soldas com um único passe sobre chapa, não se esperava alterações apreciáveis da microestrutura ao longo da zona fundida, a menos de variações na orientação dos grãos colunares. As micrografias apresentadas no trabalho foram selecionadas para representar a microestrutura típica da zona fundida resultante de cada uma das condições operacionais avaliadas.

\section{Resultados e Discussão}

As Figuras 3 e 4 mostram os oscilogramas obtidos para as 

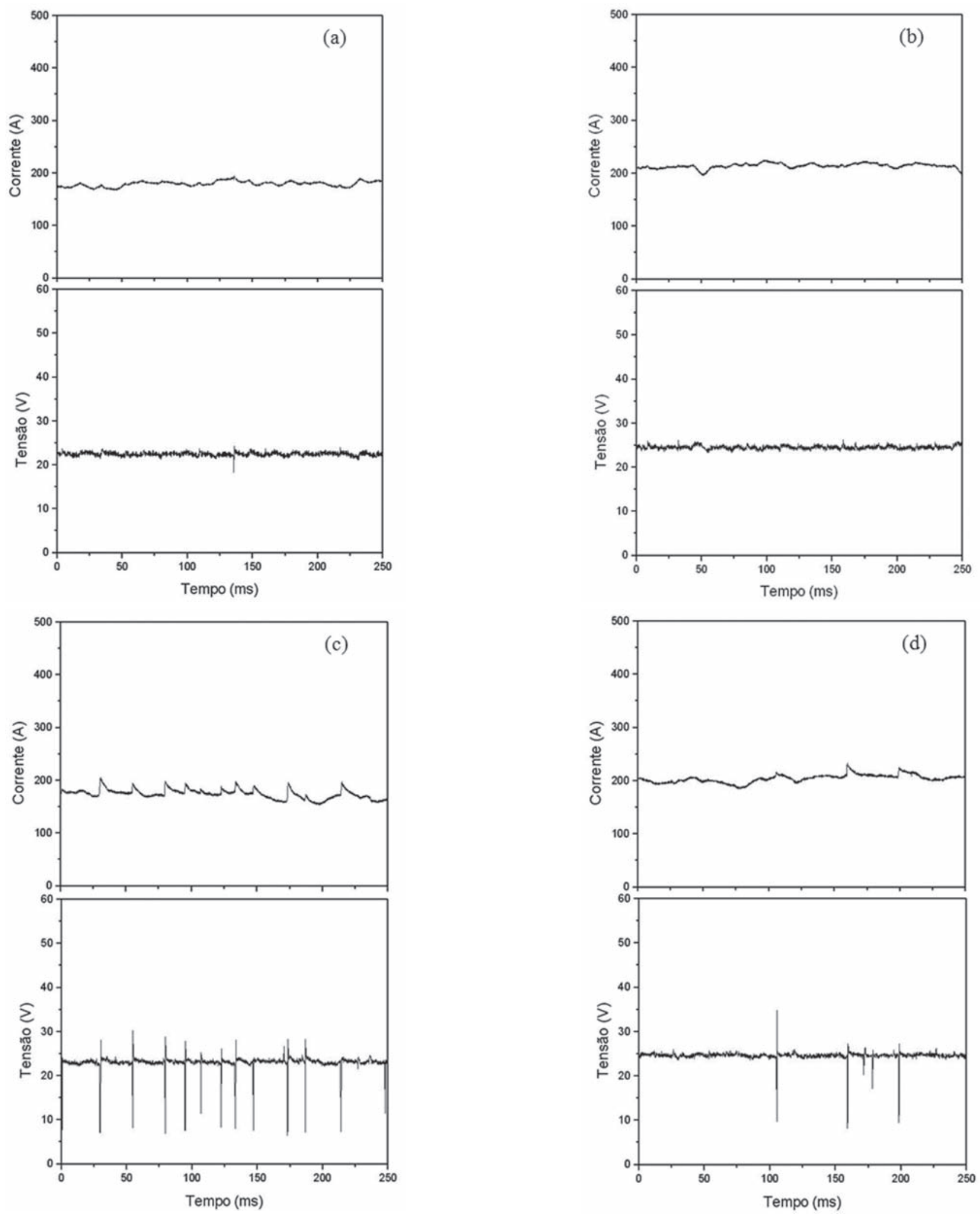

Figura 3. Oscilogramas de corrente de soldagem e tensão do arco obtidos para proteção com $75 \% \mathrm{Ar}-25 \% \mathrm{CO}_{2}$. (a) Polaridade positiva, $\mathrm{w}=7,05 \pm 0,03 \mathrm{~m} / \mathrm{mim}, \mathrm{I}=177 \pm 6 \mathrm{~A}(3,4 \%)$ e V $=22,5 \pm 0,7 \mathrm{~V}(3,1 \%)$. (b) Polaridade positiva, $\mathrm{w}=9,03 \pm 0,03 \mathrm{~m} / \mathrm{min}, \mathrm{I}=215 \pm 6 \mathrm{~A}$ $(2,8 \%)$ e V $=24,5 \pm 0,5 \mathrm{~V}(2,0 \%)$. (c) Polaridade negativa, $w=7,09 \pm 0,03 \mathrm{~m} / \mathrm{min}, \mathrm{I}=172 \pm 9 \mathrm{~A}(5,2 \%)$ e V = 23,0 $2,1 \mathrm{~V}(9,1 \%)$. (d) Polaridade negativa, $\mathrm{w}=9,00 \pm 0,03 \mathrm{~m} / \mathrm{min}, \mathrm{I}=204 \pm 7 \mathrm{~A}(3,4 \%)$ e V $=24,6 \pm 1,4 \mathrm{~V}(5,7 \%)$. w, I e V se referem, respectivamente, à "média \pm desvio padrão" dos valores de velocidade de alimentação do arame, corrente de soldagem e tensão do arco. Valores entre parênteses são os coeficientes de variação de w, I e V. 

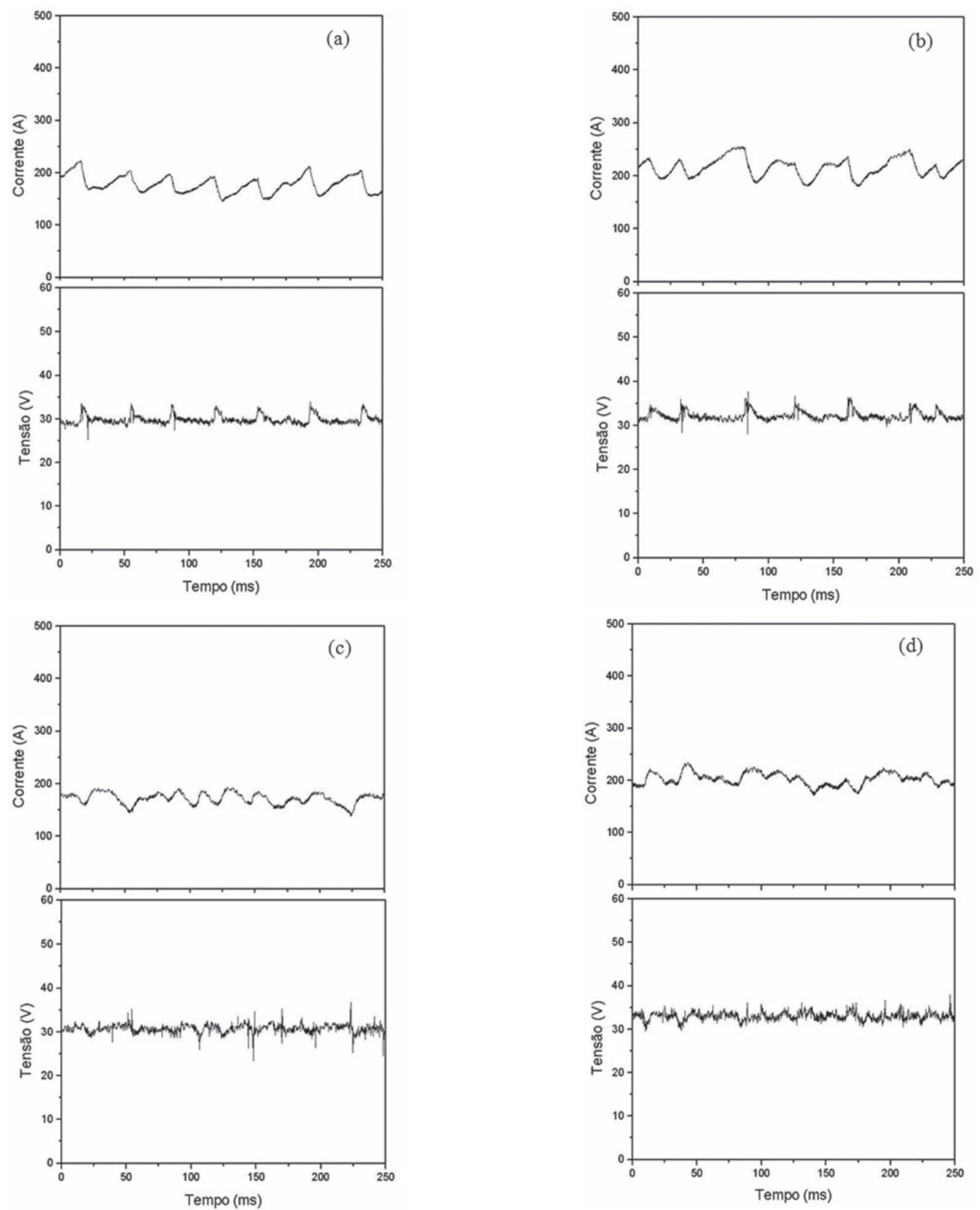

Figura 4. Oscilogramas de corrente de soldagem e tensão do arco obtidos para proteção com $100 \% \mathrm{CO}_{2}$. (a) Polaridade positiva, w $=7,07 \pm 0,04 \mathrm{~m} / \mathrm{min}, \mathrm{I}=180 \pm 16 \mathrm{~A}(8,9 \%)$ e V = 29,8 $\pm 1,0 \mathrm{~V}(3,4 \%)$. (b) Polaridade positiva, $\mathrm{w}=9,05 \pm 0,06 \mathrm{~m} / \mathrm{min}, \mathrm{I}=213 \pm 20 \mathrm{~A}$ $(9,4 \%)$ e V $=32,2 \pm 1,2 \mathrm{~V}(3,7 \%)$. (c) Polaridade negativa, $\mathrm{w}=7,05 \pm 0,02 \mathrm{~m} / \mathrm{min}, \mathrm{I}=170 \pm 11 \mathrm{~A}(6,5 \%)$ e V = 30,8 $\pm 1,0 \mathrm{~V}(3,3 \%)$. (d) Polaridade negativa, $\mathrm{w}=8,95 \pm 0,04 \mathrm{~m} / \mathrm{min}, \mathrm{I}=204 \pm 15 \mathrm{~A}(7,4 \%)$ e V $=33,0 \pm 1,1 \mathrm{~V}(3,3 \%)$. w, I e V se referem, respectivamente, à "média \pm desvio padrão" dos valores de velocidade de alimentação do arame, corrente de soldagem e tensão do arco. Valores entre parênteses são os coeficientes de variação de w, I e V. 
soldas com o arame rutílico e proteção gasosa, respectivamente, por $75 \% \mathrm{Ar}-25 \% \mathrm{CO}_{2}$ e $100 \% \mathrm{CO}_{2}$. Nas legendas são indicados a média e o desvio padrão dos valores coletados da velocidade de alimentação do arame, da corrente de soldagem e da tensão do arco e, também, a flutuação dos valores de corrente e tensão (relação entre o desvio padrão e a média correspondente). No caso da velocidade de alimentação, acredita-se que as oscilações nos valores coletados são devidas principalmente ao sistema de medição utilizado (por meio do sensor de disco óptico) e não a variações no alimentador de arame. As Figuras 5 e 6 mostram o aspecto superficial dos cordões e as macrografias e micrografias obtidas de suas seções transversais para as soldas com proteção, respectivamente, por $75 \% \mathrm{Ar}-25 \% \mathrm{CO}_{2}$ e $100 \% \mathrm{CO}_{2}$. Nessas figuras, os resultados são apresentados para as diferentes polaridades e velocidades de alimentação do arame avaliadas.

A Tabela 1 indica os valores da energia de soldagem, das eficiências de deposição do arame tubular rutílico e das taxas correspondentes de deposição. Em função da utilização de uma fonte do tipo "tensão constante" e de condições de soldagem sem a ocorrência ou com poucos curtos-circuitos, a energia de soldagem foi calculada considerando-se a potência média aritmética do arco, ou seja, a partir do produto dos valores médios da corrente de soldagem e da tensão do arco, dividido pela velocidade de soldagem ajustada. A Tabela 2 mostra os parâmetros geométricos e a diluição obtida para os cordões de solda. As Tabelas 3 e 4 indicam, respectivamente, a fração volumétrica dos microconstituintes presentes na zona fundida e a dureza dessa região, considerando-se o intervalo de confiança de $95 \%$. Nessas tabelas, os resultados são apresentados para as diferentes polaridades, velocidades de alimentação do arame e gases de proteção avaliados.

\subsection{Efeito da Velocidade de Alimentação do Arame}

De acordo com as Figuras 3 e 4, observa-se que, como esperado, um aumento na velocidade de alimentação do arame (nominalmente de 7 para $9 \mathrm{~m} / \mathrm{min}$ ) resulta em um aumento no valor médio da corrente de soldagem (variação máxima de 177 para 215 A) e, como o comprimento do arco foi mantido constante, também em um aumento correspondente no valor da tensão média do arco (variação máxima de 29,8 para $32,2 \mathrm{~V}$ ). Este efeito foi verificado para os dois gases de proteção e polaridades do eletrodo avaliados. $\mathrm{Na}$ soldagem com $100 \% \mathrm{CO}_{2}$ (para as duas polaridades), um aumento na velocidade de alimentação do arame resulta em um aumento na flutuação dos valores de corrente de soldagem e tensão do arco (aumento na relação entre o desvio padrão e a média destes parâmetros), indicando uma redução da estabilidade operacional. Entretanto, verifica-se um comportamento inverso na soldagem com $75 \% \mathrm{Ar}-25 \% \mathrm{CO}_{2}$ para as duas polaridades, ou seja, a estabilidade operacional aumenta com o aumento da velocidade de alimentação do arame. Esta diferença de comportamento pode estar associada com efeitos distintos (dependendo do tipo de gás de proteção) do aumento da corrente de soldagem nos parâmetros da transferência metálica do arame tubular rutílico, sendo comprovada por Starling e Modenesi[4] que estudaram, pela técnica de perfilografia (shadowgrafia), a transferência metálica do mesmo arame tubular rutílico na soldagem com polaridade positiva e proteção por $75 \% \mathrm{Ar}-25 \% \mathrm{CO}_{2}$ ou $100 \% \mathrm{CO}_{2}$ em condições essencialmente sem a ocorrência de curtos-circuitos. De uma forma geral, os autores perceberam que um aumento na corrente de soldagem resulta em uma redução no tamanho médio das gotas de metal e em um aumento na frequiência de destacamento das mesmas. Também perceberam que, na soldagem com os dois gases, a transferência metálica é do tipo globular com a formação de uma coluna de fluxo projetada em direção à poça. Entretanto, na soldagem com $75 \% \mathrm{Ar}-25 \% \mathrm{CO}_{2}$ para valores mais baixos de corrente a gota metálica e o fluxo são transferidos independentemente para a poça de fusão, sendo que a coluna de fluxo parece retardar a transferência da gota. Em alguns momentos, esta coluna chega a tocar a poça de fusão, devendo gerar perturbações no arco e resultar nas maiores flutuações observadas dos valores de corrente de soldagem e tensão do arco. Para valores mais altos de corrente a gota metálica se deforma pela ação da coluna de fluxo não tendo mais um formato tipicamente circular. Nesse caso, a coluna de fluxo parece ainda estar dificultando a transição para a transferência spray. Por outro lado, na soldagem com $100 \% \mathrm{CO}_{2}$ para valores mais baixos de corrente nota-se que a coluna de fluxo retarda a transferência da gota de metal para a poça, a qual parece ocorrer somente após a sua mistura com o material do fluxo. Nesse caso, a coluna de fluxo não chega a tocar a poça. Para valores mais altos de corrente a gota metálica e o fluxo passam a se transferir independentemente para a poça de fusão, devendo gerar perturbações no arco e resultar nas maiores flutuações observadas dos valores de corrente de soldagem e tensão do arco.

De acordo com a Tabela 1, nota-se que na soldagem com $100 \% \mathrm{CO}_{2}$ e polaridade negativa ocorre uma redução na eficiência de deposição (de 72 para $64 \%$ ) com o aumento da velocidade de alimentação, também indicando uma redução da estabilidade operacional. A Figura 6 mostra que todas as soldas com $100 \% \mathrm{CO}_{2}$ apresentam respingos e cordões com algumas irregularidades superficiais sendo que, na polaridade negativa, um aumento na velocidade de alimentação resulta em um aumento no nível de respingos, também revelando uma redução na estabilidade operacional. Ainda de acordo com a Tabela 1, nota-se que na soldagem com $75 \% \mathrm{Ar}-25 \% \mathrm{CO}_{2}$ (nas duas polaridades) um aumento na velocidade de alimentação não resulta em maiores variações na eficiência de deposição (variação máxima de 84 para $87 \%$ ). As soldas com $75 \% \mathrm{Ar}-25 \% \mathrm{CO}_{2}$ (Figura 5) apresentam cordões mais regulares superficialmente que as soldas com $100 \% \mathrm{CO}_{2}$ (Figura 6). De acordo com a Figura 5, as soldas com $75 \% \mathrm{Ar}-25 \% \mathrm{CO}_{2}$ e polaridade positiva não apresentam respingos, entretanto, nas soldas com polaridade negativa percebe-se a presença de respingos. Ainda de acordo com a Figura 5, percebese que na soldagem com $75 \% \mathrm{Ar}-25 \% \mathrm{CO}_{2}$ e polaridade negativa ocorre uma redução no nível de respingos com o aumento na velocidade de alimentação do arame, revelando um aumento na estabilidade operacional. Isto é consistente com os oscilogramas apresentados na Figura 3 para a soldagem com $75 \% \mathrm{Ar}-25 \% \mathrm{CO}_{2}$ e polaridade negativa que indicam uma redução no número de curtos-circuitos com o aumento da velocidade de alimentação do arame. 

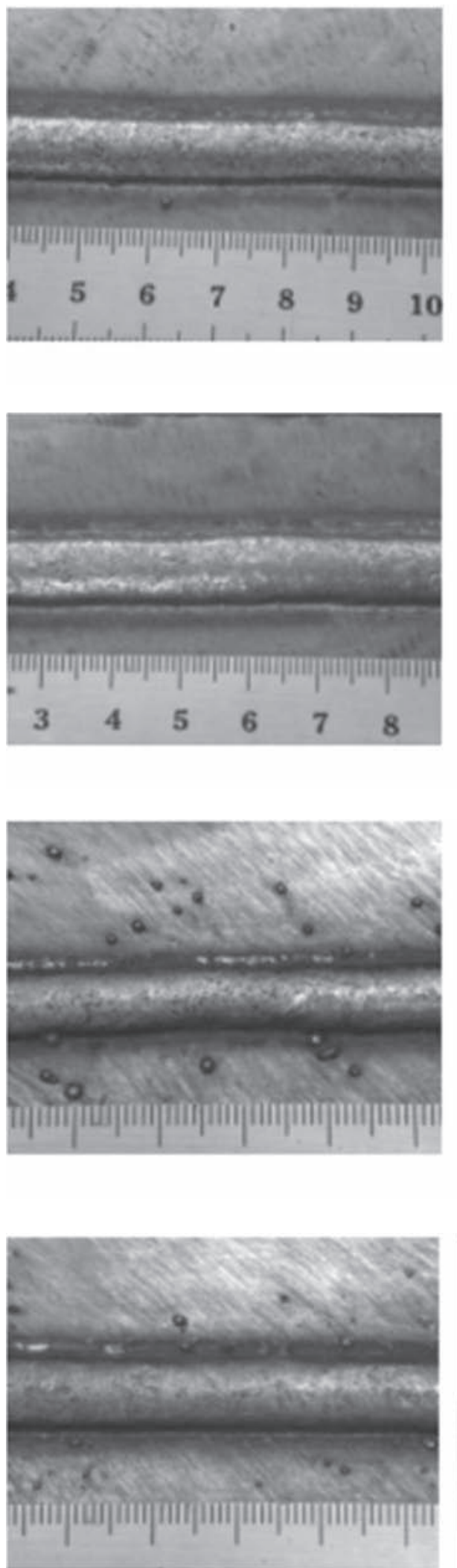

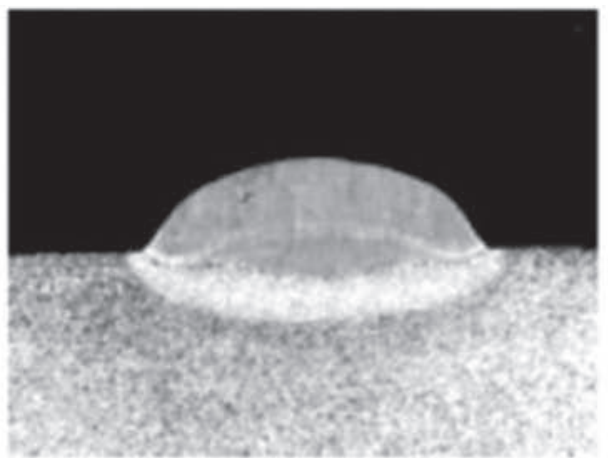

(a)

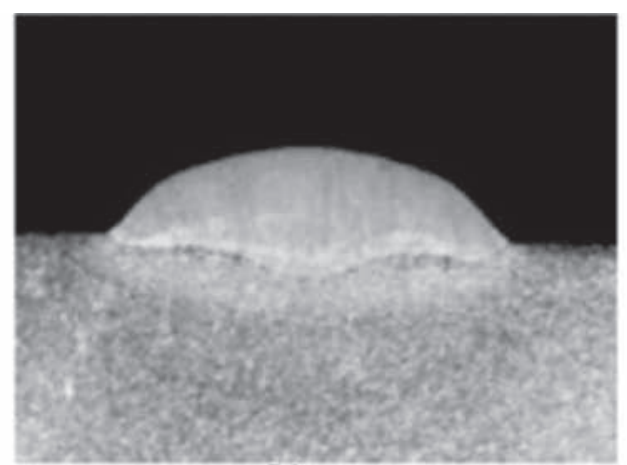

(b)

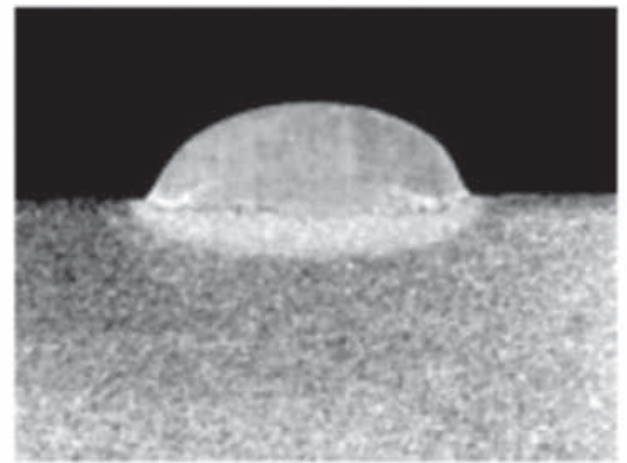

(c)

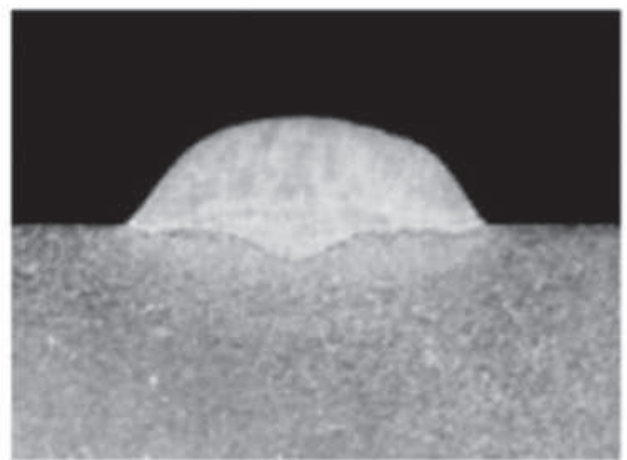

(d)
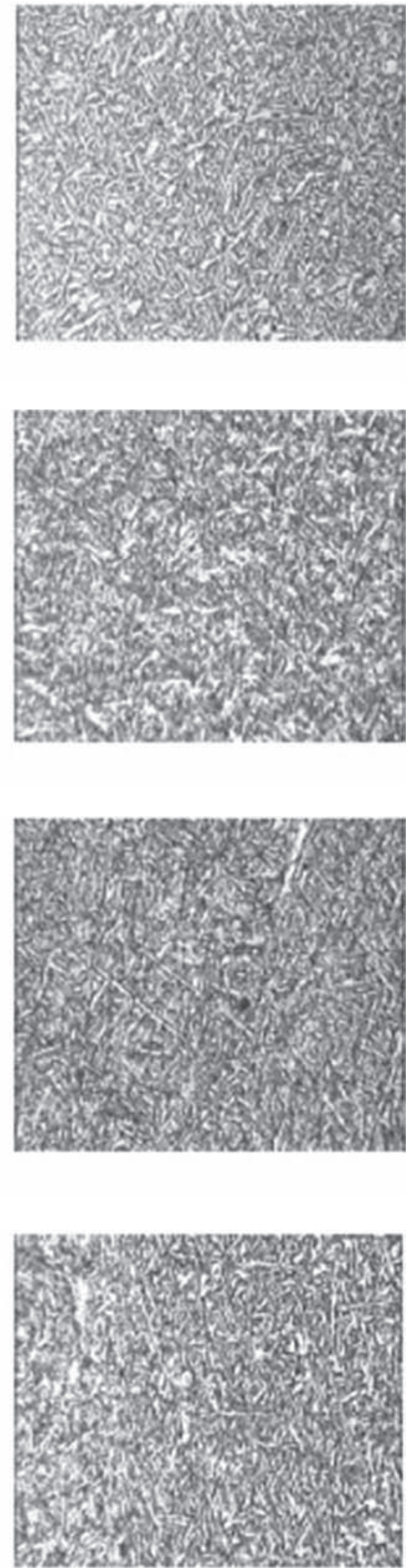

Figura 5. Cordões obtidos para as soldas do arame tubular rutílico com $75 \% \mathrm{Ar}-25 \% \mathrm{CO}_{2}$. Aspecto superficial (esquerda). Macrografia - Nital $10 \%$ (centro). Micrografia - MO, aumento original 500 X, Nital $2 \%$ (direita). (a) Polaridade positiva, velocidade de alimentação nominal de $7 \mathrm{~m} / \mathrm{min}$. (b) Polaridade positiva, velocidade de alimentação nominal de $9 \mathrm{~m} / \mathrm{min}$. (c) Polaridade negativa, velocidade de alimentação nominal de $7 \mathrm{~m} / \mathrm{min}$. (d) Polaridade negativa, velocidade de alimentação nominal de $9 \mathrm{~m} / \mathrm{min}$. 

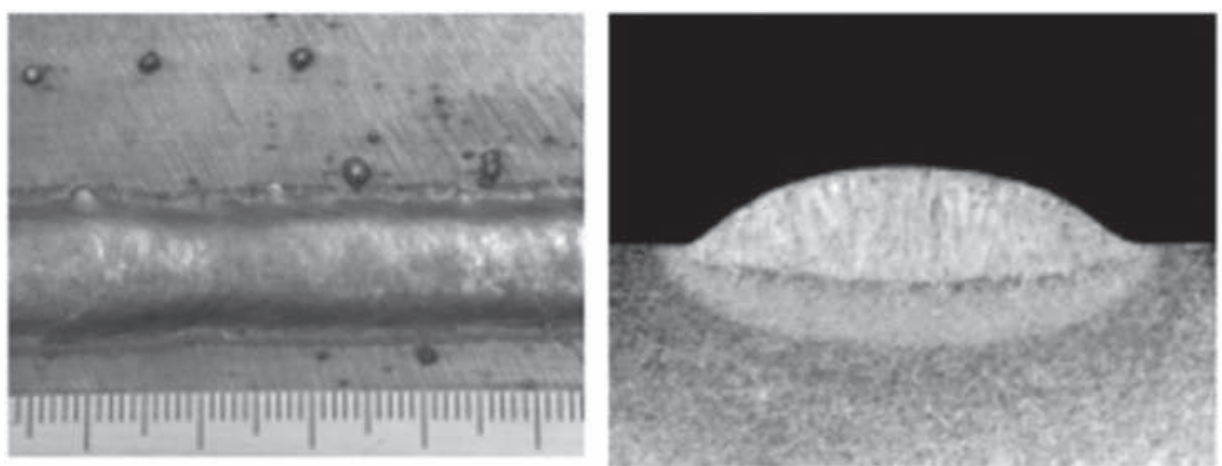

(a)
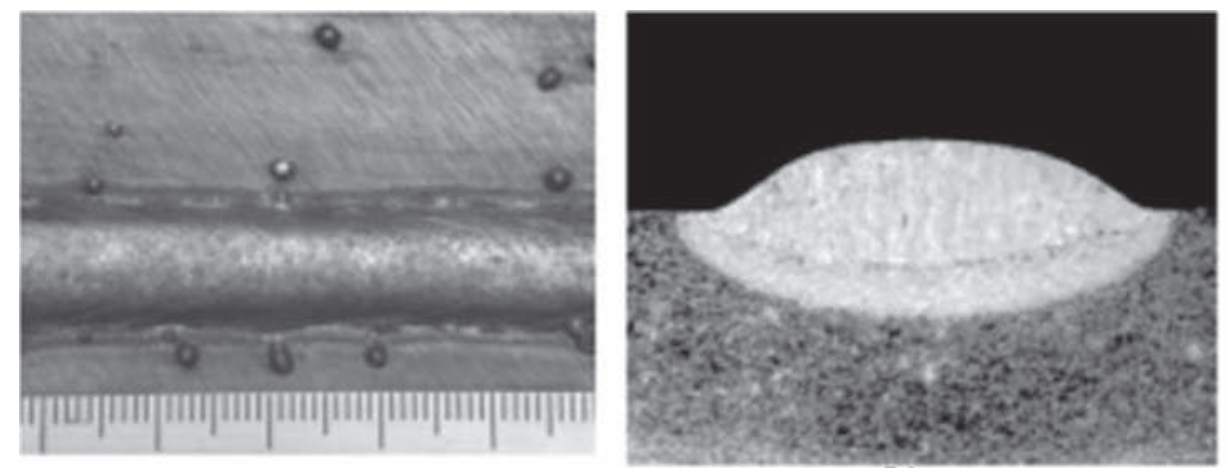

(b)
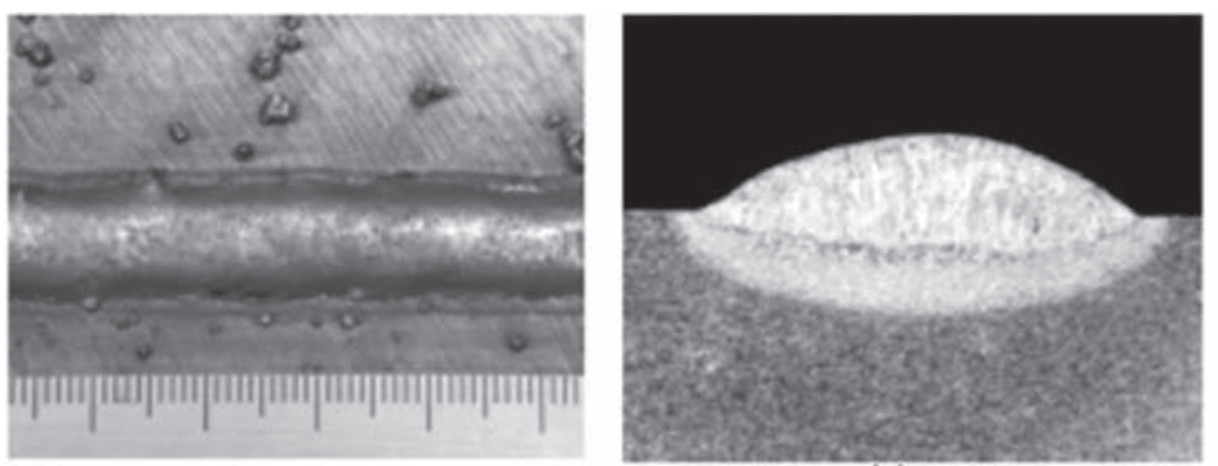

(c)
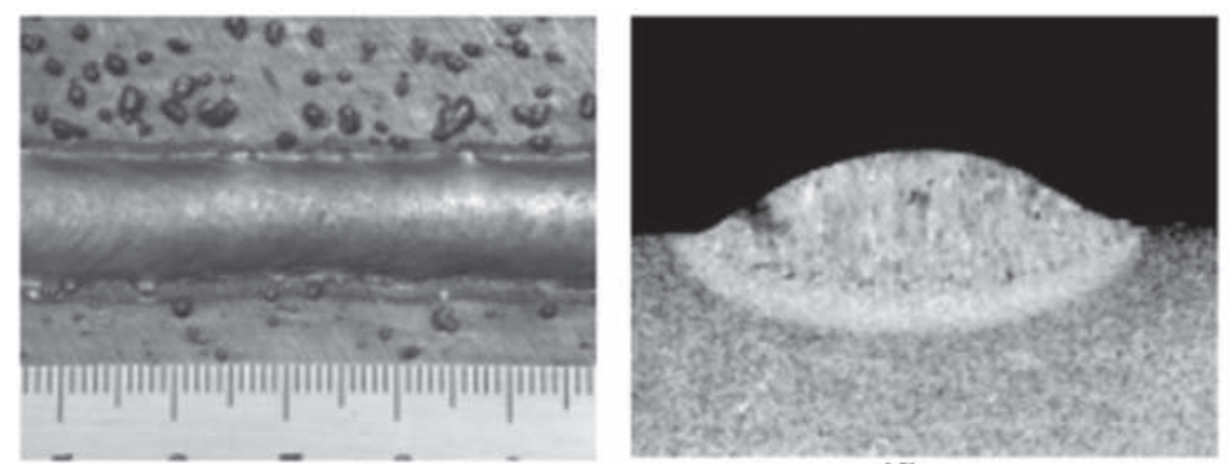

(d)
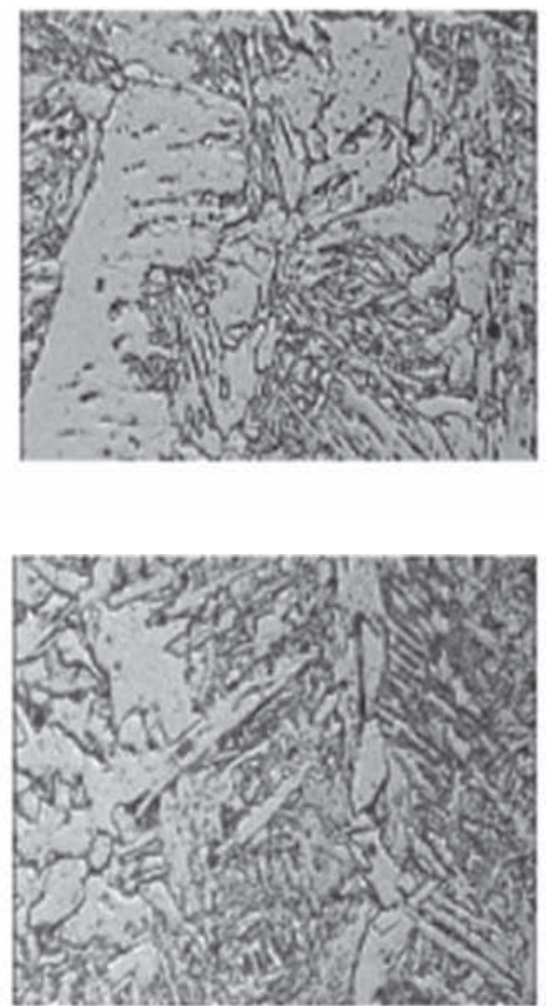

Figura 6. Cordões obtidos para as soldas do arame tubular rutílico com $100 \% \mathrm{CO}_{2}$. Aspecto superficial (esquerda). Macrografia - Nital $10 \%$ (centro). Micrografia - MO, aumento original 500 X, Nital $2 \%$ (direita). (a) Polaridade positiva, velocidade de alimentação nominal de $7 \mathrm{~m} / \mathrm{min}$. (b) Polaridade positiva, velocidade de alimentação nominal de $9 \mathrm{~m} / \mathrm{min}$. (c) Polaridade negativa, velocidade de alimentação nominal de $7 \mathrm{~m} / \mathrm{min}$. (d) Polaridade negativa, velocidade de alimentação nominal de $9 \mathrm{~m} / \mathrm{min}$. 
A Tabela 2 e as macrografias das Figuras 5 e 6 indicam que um aumento na velocidade de alimentação do arame, para um mesmo tipo de gás de proteção e polaridade do eletrodo, afeta a geométrica do cordão, resultando em aumentos da largura (variação máxima de 10,0 para $11,3 \mathrm{~mm}$ ), penetração máxima (variação máxima de 1,2 para 2,1 mm), área depositada (variação máxima de 18,0 para $20,2 \mathrm{~mm}^{2}$ ), área de penetração (variação máxima de 11,5 para $18,9 \mathrm{~mm}^{2}$ ) e diluição (variação máxima de 41,6 para 52,4\%). Entretanto, as variações no reforço parecem depender do gás de proteção e da polaridade do eletrodo.

Como descrito na metodologia, um aumento da velocidade de alimentação (de 7 para $9 \mathrm{~m} / \mathrm{min}$ ) era acompanhado de um aumento proporcional da velocidade de soldagem (de 4,7 para $6 \mathrm{~mm} / \mathrm{s}$ ) de forma a se manter constante o volume da poça de fusão. Dessa forma, o aumento da velocidade de alimentação, apesar de resultar em um aumento nos valores médios da corrente de soldagem e da tensão do arco (Figuras 3 e 4), não resultava em variações significativas na energia de soldagem para um mesmo gás de proteção e polaridade do eletrodo (variação máxima de 0,85 para $0,88 \mathrm{~kJ} / \mathrm{mm}$, Tabela 1 ). Assim, como o comprimento do arco também foi mantido constante $(3,5 \mathrm{~mm})$, acreditase que a variação observada na geometria do cordão quando se aumenta a velocidade de alimentação do arame decorra principalmente dos efeitos concorrentes da corrente de soldagem e da velocidade de soldagem. Com o aumento da corrente, uma maior quantidade de calor é transferida para a peça pelas regiões de queda catódica (na soldagem com o eletrodo positivo) ou de queda anódica (na soldagem com o eletrodo negativo) [18]. Por outro lado, um aumento da velocidade de soldagem implica em uma redução da quantidade de calor fornecido à junta por unidade de comprimento desta. Dessa forma, na faixa operacional avaliada no presente trabalho, o efeito da corrente foi preponderante na determinação dos aumentos observados da largura, penetração máxima e área de penetração. Apesar da manutenção da proporção entre a velocidade de alimentação do arame e da velocidade de soldagem, percebeu-se uma tendência de pequeno aumento da área depositada com o aumento da velocidade de alimentação. Uma explicação poderia ser um aumento da eficiência de deposição com o aumento da velocidade de alimentação, entretanto, de acordo com a Tabela 1 , não se verifica esta tendência. Dessa forma, acredita-se esta variação na área depositada, além das incertezas associadas à sua medida (decorrentes, por exemplo, do arredondamento das arestas e da resolução do sistema de medição), também decorra de erros experimentais nos ajustes das velocidades de alimentação e de soldagem. Outra possiblidade para a variação da área depositada se refere às dispersões inerentes ao processo de soldagem. Assim, variações localizadas no cordão (com a formação de picos e vales) também podem resultar em erros na avaliação da área depositada. O aumento da diluição com o aumento da velocidade de alimentação é consistente com as menores variações observadas na área depositada em relação à área de penetração.

Tabela 1. Energia de Soldagem $(H)$, eficiência de deposição $\left(\varphi_{\text {tubular }}\right)$ do arame (média avaliada em pelo menos duas soldas) e valor da taxa de deposição $\left(\mathrm{TD}_{\text {tubular }}\right)$. $\mathrm{w}$ - velocidade de alimentação nominal do arame.

\begin{tabular}{c|c|c|c|c|c}
\hline $\begin{array}{c}\text { Polaridade } \\
\text { Eletrodo }\end{array}$ & $\begin{array}{c}\text { Gás } \\
\text { Proteção }\end{array}$ & $\begin{array}{c}\mathrm{W} \\
(\mathrm{m} / \mathrm{min})\end{array}$ & $\begin{array}{c}\mathrm{H} \\
(\mathrm{kJ} / \mathrm{mm})\end{array}$ & $\begin{array}{c}\varphi_{\text {tubular }} \\
(\%)\end{array}$ & $\begin{array}{c}\mathrm{TD}_{\text {tubular }} \\
(\mathrm{kg} / \mathrm{h})\end{array}$ \\
\hline \multirow{3}{*}{ Positiva } & $75 \% \mathrm{Ar}-25 \% \mathrm{CO}_{2}$ & 7 & 0,85 & 89 & 2,59 \\
\cline { 3 - 6 } & & 9 & 0,88 & 88 & 3,29 \\
\cline { 2 - 6 } & $100 \% \mathrm{CO}_{2}$ & 7 & 1,14 & 85 & 2,47 \\
\cline { 3 - 6 } & & 9 & 1,14 & 81 & 3,03 \\
\hline \multirow{2}{*}{ Negativa } & $75 \% \mathrm{Ar}-25 \% \mathrm{CO}_{2}$ & 7 & 0,84 & 84 & 2,44 \\
\cline { 3 - 6 } & & 9 & 0,84 & 87 & 3,25 \\
\cline { 2 - 6 } & $100 \% \mathrm{CO}_{2}$ & 7 & 1,11 & 72 & 2,09 \\
\cline { 2 - 6 } & & 9 & 1,12 & 64 & 2,39 \\
\hline
\end{tabular}

Tabela 2. Parâmetros obtidos para os cordões de solda (média dos valores avaliados em duas macrografias). w - velocidade de alimentação nominal do arame, $\mathrm{W}$ - largura, $\mathrm{h}$ - reforço, $\mathrm{P}_{\max }$ - penetração máxima, $\mathrm{A}_{\mathrm{d}}$ - área depositada, $\mathrm{A}_{\mathrm{p}}$ - área de penetração e $\delta$ - diluição.

\begin{tabular}{|c|c|c|c|c|c|c|c|c|}
\hline $\begin{array}{c}\text { Polaridade } \\
\text { Eletrodo }\end{array}$ & $\begin{array}{c}\text { Gás } \\
\text { Proteção }\end{array}$ & $\begin{array}{c}\mathrm{W} \\
(\mathrm{m} / \mathrm{min})\end{array}$ & $\begin{array}{c}\mathrm{W} \\
(\mathrm{mm})\end{array}$ & $\begin{array}{c}\mathrm{h} \\
(\mathrm{mm})\end{array}$ & $\begin{array}{l}\mathrm{P}_{\max } \\
(\mathrm{mm})\end{array}$ & $\begin{array}{c}\mathrm{A}_{\mathrm{d}} \\
\left(\mathrm{mm}^{2}\right)\end{array}$ & $\begin{array}{c}\mathrm{A}_{\mathrm{p}} \\
\left(\mathrm{mm}^{2}\right)\end{array}$ & $\begin{array}{c}\delta \\
(\%)\end{array}$ \\
\hline \multirow{4}{*}{ Positiva } & \multirow{2}{*}{$75 \% \mathrm{Ar}-25 \% \mathrm{CO}_{2}$} & 7 & 10,0 & 2,7 & 0,9 & 18,2 & 5,2 & 22,2 \\
\hline & & 9 & 11,3 & 2,5 & 1,1 & 19,1 & 7,0 & 27,0 \\
\hline & \multirow{2}{*}{$100 \% \mathrm{CO}_{2}$} & 7 & 12,3 & 2,1 & 1,2 & 16,4 & 11,5 & 41,6 \\
\hline & & 9 & 12,8 & 2,1 & 2,1 & 17,2 & 18,9 & 52,4 \\
\hline \multirow{4}{*}{ Negativa } & \multirow{2}{*}{$75 \% \mathrm{Ar}-25 \% \mathrm{CO}_{2}$} & 7 & 9,4 & 2,7 & 0,6 & 18,0 & 3,5 & 16,4 \\
\hline & & 9 & 10,2 & 2,9 & 1,0 & 20,2 & 4,6 & 18,6 \\
\hline & \multirow{2}{*}{$100 \% \mathrm{CO}_{2}$} & 7 & 11,3 & 2,4 & 1,6 & 16,3 & 12,1 & 42,5 \\
\hline & & 9 & 12,1 & 2,4 & 1,7 & 16,5 & 16,7 & 50,2 \\
\hline
\end{tabular}


Tabela 3. Fração volumétrica dos microconstituintes presentes na zona fundida. Intervalo de confiança: $95 \%$.

\begin{tabular}{|c|c|c|c|c|c|c|c|}
\hline $\begin{array}{c}\text { Polaridade } \\
\text { Eletrodo }\end{array}$ & $\begin{array}{c}\text { Gás } \\
\text { Proteção }\end{array}$ & $\begin{array}{c}\mathrm{w} \\
(\mathrm{m} / \mathrm{min})\end{array}$ & $\begin{array}{c}\mathrm{PF}(\mathrm{G}) \\
(\%)\end{array}$ & $\begin{array}{l}\mathrm{PF}(\mathrm{I}) \\
(\%)\end{array}$ & $\begin{array}{l}\mathrm{AF} \\
(\%)\end{array}$ & $\begin{array}{c}\text { FS(NA) } \\
(\%)\end{array}$ & $\begin{array}{c}\text { FS(A) } \\
(\%)\end{array}$ \\
\hline \multirow{4}{*}{ Positiva } & \multirow{2}{*}{$75 \% \mathrm{Ar}-25 \% \mathrm{CO}_{2}$} & 7 & $2,7 \pm 0,7$ & $0,2 \pm 0,2$ & $25,2 \pm 1,8$ & $67,1 \pm 2,0$ & $4,8 \pm 1,0$ \\
\hline & & 9 & $2,6 \pm 0,7$ & $0,3 \pm 0,2$ & $31,5 \pm 2,1$ & $57,2 \pm 2,25$ & $8,3 \pm 1,4$ \\
\hline & \multirow{2}{*}{$100 \% \mathrm{CO}_{2}$} & 7 & $25,8 \pm 2,4$ & $6,9 \pm 1,2$ & $29,1 \pm 2,9$ & $23,0 \pm 2,4$ & $15,1 \pm 1,9$ \\
\hline & & 9 & $26,8 \pm 2,9$ & $6,7 \pm 1,2$ & $30,3 \pm 2,8$ & $22,5 \pm 2,8$ & $13,8 \pm 1,9$ \\
\hline \multirow{4}{*}{ Negativa } & \multirow{2}{*}{$75 \% \mathrm{Ar}-25 \% \mathrm{CO}_{2}$} & 7 & $2,2 \pm 0,6$ & $0,2 \pm 0,2$ & $32,8 \pm 2,3$ & $58,0 \pm 2,5$ & $6,9 \pm 1,2$ \\
\hline & & 9 & $4,5 \pm 1,0$ & $0,1 \pm 0,1$ & $27,6 \pm 2,3$ & $61,5 \pm 2,6$ & $6,7 \pm 1,2$ \\
\hline & \multirow{2}{*}{$100 \% \mathrm{CO}_{2}$} & 7 & $26,7 \pm 2,6$ & $6,7 \pm 1,2$ & $28,6 \pm 2,6$ & $24,8 \pm 2,7$ & $13,2 \pm 1,9$ \\
\hline & & 9 & $25,3 \pm 2,3$ & $6,5 \pm 1,1$ & $30,0 \pm 2,9$ & $23,5 \pm 2,3$ & $14,6 \pm 2,1$ \\
\hline
\end{tabular}

$\mathrm{PF}(\mathrm{G})$ - ferrita primária de contorno de grão; $\mathrm{PF}(\mathrm{I})$ - ferrita primária intragranular; $\mathrm{AF}$ - ferrita acicular; FS(NA) e FS(A) - ferritas com segunda fase não alinhada e alinhada. w - velocidade de alimentação nominal.

Tabela 4. Dureza Vickers (HV) na zona fundida. Intervalo de confiança: $95 \%$. w - velocidade de alimentação nominal.

\begin{tabular}{|c|c|c|c|}
\hline $\begin{array}{l}\text { Polaridade } \\
\text { Eletrodo }\end{array}$ & $\begin{array}{c}\text { Gás } \\
\text { Proteção }\end{array}$ & $\begin{array}{c}\mathrm{W} \\
(\mathrm{m} / \mathrm{min})\end{array}$ & $\begin{array}{c}\mathrm{HV} \\
(98,1 \mathrm{~N})\end{array}$ \\
\hline \multirow{4}{*}{ Positiva } & \multirow{2}{*}{$75 \% \mathrm{Ar}-25 \% \mathrm{CO}_{2}$} & 7 & $278 \pm 7$ \\
\hline & & 9 & $203 \pm 37$ \\
\hline & \multirow{2}{*}{$100 \% \mathrm{CO}_{2}$} & 7 & $184 \pm 4$ \\
\hline & & 9 & $181 \pm 6$ \\
\hline \multirow{4}{*}{ Negativa } & \multirow{2}{*}{$75 \% \mathrm{Ar}-25 \% \mathrm{CO}_{2}$} & 7 & $259 \pm 16$ \\
\hline & & 9 & $235 \pm 9$ \\
\hline & \multirow{2}{*}{$100 \% \mathrm{CO}_{2}$} & 7 & $179 \pm 4$ \\
\hline & & 9 & $182 \pm 5$ \\
\hline
\end{tabular}

Observando-se as microestruturas das Figuras 5 e 6 e os resultados da metalografia quantitativa apresentados na Tabela 3 , percebe-se que um aumento na velocidade de alimentação do arame, para um mesmo tipo de gás de proteção e polaridade do eletrodo, não afetou fortemente a microestrutura da zona fundida. Isto é consistente com o fato da energia de soldagem não ter variado significativamente com o aumento da velocidade de alimentação (Tabela 1), resultando em pequenas variações na velocidade de resfriamento das soldas. Entretanto, de acordo com a Tabela 2, para um mesmo gás de proteção e polaridade do eletrodo, percebe-se algum aumento da diluição (variação máxima de 41,6 para $52,4 \%$ ) com o aumento da velocidade de alimentação devendo, assim, resultar em alguma variação na composição química da zona fundida. Os resultados indicam que esta variação na composição química também não deve ter sido forte o suficiente para resultar em maiores alterações microestruturais. Entretanto, a variação na composição química pode ter contribuído para a tendência de redução da dureza com o aumento da velocidade de alimentação do arame na soldagem com $75 \% \mathrm{Ar}-25 \% \mathrm{CO}_{2}$ para uma mesma polaridade do eletrodo (variação máxima de 278 para $203 \mathrm{HV}$ ), como observado na Tabela 4.

\subsection{Efeito do Gás de Proteção}

Pelas Figuras 3 e 4 observa-se também que, para uma mesma polaridade do eletrodo e velocidade de alimentação do arame, um aumento do teor de $\mathrm{CO}_{2}$ no gás de proteção (soldagem com $100 \% \mathrm{CO}_{2}$ em relação à soldagem com $75 \% \mathrm{Ar}-25 \% \mathrm{CO}_{2}$ ) resulta em pequenas variações na corrente média de soldagem (variação máxima de 177 para 180 A) e em um aumento na tensão média do arco (variação máxima de 24,6 para 33,0 V). Este aumento da tensão do arco pode estar associado à maior condutividade térmica do gás constituído por $\mathrm{CO}_{2}$ puro[19]. A condutividade térmica do gás afeta fortemente o fluxo de elétrons na coluna do arco. Gases de alta condutividade térmica devem aumentar a resistividade do arco e podem exigir, para corrente de soldagem e comprimento de arco equivalentes, um aumento na tensão do arco. Ainda de acordo com as Figuras 3 e 4, percebe-se que um aumento do teor de $\mathrm{CO}_{2}$ no gás de proteção (para uma mesma velocidade de alimentação do arame) também resulta em uma maior flutuação nos valores de corrente de soldagem (polaridades positiva e negativa) e em uma maior (polaridade positiva) ou menor (polaridade negativa) flutuação nos valores de tensão do arco. Dessa forma, o aumento do teor de $\mathrm{CO}_{2}$ sugere uma redução da estabilidade operacional do processo 
FCAW de forma similar ao que ocorre no processo GMAW. No estudo sobre transferência metálica do mesmo arame tubular rutílico utilizado no presente trabalho, Starling e Modenesi[4] também perceberam que, na polaridade avaliada (positiva) e em um mesmo nível de corrente, a transferência globular ocorre com um maior tamanho das gotas de metal na soldagem com $100 \% \mathrm{CO}_{2}$ e com uma maior frequiência de destacamento das gotas na soldagem com $75 \% \mathrm{Ar}-25 \% \mathrm{CO}_{2}$. Isto indicaria uma tendência de maiores variações no comprimento efetivo do arco na soldagem com $100 \% \mathrm{CO}_{2} \mathrm{e}$, assim, nas maiores flutuações dos valores de corrente de soldagem e tensão do arco observadas no presente trabalho para o mesmo gás de proteção.

De acordo com a Tabela 1, nota-se que, para uma mesma polaridade do eletrodo e velocidade de alimentação do arame, um aumento do teor de $\mathrm{CO}_{2}$ no gás de proteção resulta em alguma redução na eficiência de deposição, entretanto, esta redução é mais significativa na soldagem com a polaridade negativa (variação máxima de 87 para $64 \%$ ). Pelas Figuras 5 e 6 também se percebe que um aumento do teor de $\mathrm{CO}_{2}$, para uma mesma polaridade do eletrodo e velocidade de alimentação do arame, também resulta em um aumento do nível de respingos e em cordões com algumas irregularidades superficiais. Estes efeitos também são evidências da redução da estabilidade operacional quando se aumenta o teor de $\mathrm{CO}_{2}$ no gás de proteção na soldagem com o arame tubular rutílico. Também se percebe que os respingos formados nas soldas com $100 \% \mathrm{CO}_{2}$ são mais grosseiros do que aqueles formados nas soldas com $75 \% \mathrm{Ar}-$ $25 \% \mathrm{CO}_{2}$ indicando para o primeiro gás a tendência de formação de gotas de metal mais grosseiras durante a transferência metálica.

A Tabela 2 e as macrografias das Figuras 5 e 6 indicam que um aumento um aumento do teor de $\mathrm{CO}_{2}$ no gás de proteção, para uma mesma velocidade de alimentação do arame e polaridade do eletrodo, afeta a geometria do cordão, resultando em aumentos da largura (variação máxima de 10,0 para $12,3 \mathrm{~mm}$ ), penetração máxima (variação máxima de 0,6 para $1,6 \mathrm{~mm}$ ), área de penetração (variação máxima de 4,6 para $16,7 \mathrm{~mm}^{2}$ ) e diluição (variação máxima de 18,6 para 50,2 \%) e, também, em reduções no reforço (variação máxima de 2,7 para $2,1 \mathrm{~mm}$ ) e na área depositada (variação máxima de 20,2 para $16,5 \mathrm{~mm}^{2}$ ). É sabido que o aumento do teor de $\mathrm{CO}_{2}$ no gás de proteção aumenta a condutividade térmica da coluna de plasma, promovendo uma maior transferência de calor para a peça. Como discutido, o aumento da condutividade térmica também se reflete em um aumento na tensão média do arco, resultando em um aumento da energia de soldagem com o aumento do teor de $\mathrm{CO}_{2}$ no gás de proteção (variação máxima de 0,85 para $1,14 \mathrm{~kJ} / \mathrm{mm}$, Tabela 1), podendo, assim, também resultar em um aumento no calor imposto à peça. Estes fatores justificariam os aumentos da largura, penetração máxima e área de penetração com o aumento do teor de $\mathrm{CO}_{2}$ observados no presente trabalho, da mesma forma como ocorre na soldagem com arames maciços. A redução na eficiência de deposição com o aumento do teor de $\mathrm{CO}_{2}$ no gás de proteção (Tabela 1) justificaria a redução observada da área depositada com o aumento do teor de $\mathrm{CO}_{2}$, mesmo com a manutenção da razão entre as velocidades de alimentação e de soldagem. A redução da área depositada, associada aos aumentos da área de penetração e da largura, também justificaria o aumento da diluição e a redução do reforço observados no presente trabalho com o aumento do teor de $\mathrm{CO}_{2}$.

Observando-se as microestruturas das Figuras 5 e 6 e os resultados da metalografia quantitativa apresentados na Tabela 3 , percebe-se que um aumento do teor de $\mathrm{CO}_{2}$ no gás de proteção afeta a microestrutura da zona fundida. De uma forma geral, um aumento do teor de $\mathrm{CO}_{2}$ (mantendo uma mesma velocidade de alimentação do arame e polaridade do eletrodo) resulta principalmente em aumentos nas frações de ferrita primária de contorno de grão (PG(G), variação máxima de 2,2 para 26,7 \%), ferrita primária intragranular $(\mathrm{PF}(\mathrm{I})$, variação máxima de 0,2 para $6,9 \%$ ) e de ferrita com segunda fase alinhada (FS(A), variação máxima de 4,8 para $15,1 \%$ ) às custas da redução da fração de ferrita com segunda fase não alinhada (FA(NA), variação máxima de 67,1 para 23,0 \%). Da mesma forma, percebe-se que a microestrutura resultante das soldas com $100 \% \mathrm{CO}_{2}$ (Figura 6) é mais grosseira que a resultante das soldas com $75 \% \mathrm{Ar}-25 \% \mathrm{CO}_{2}$ (Figura 5). Nota-se também que um aumento do teor de $\mathrm{CO}_{2}$ (mantendo uma mesma velocidade de alimentação do arame e polaridade do eletrodo) também resulta em uma tendência de redução da dureza da zona fundida (variação máxima de 259 para $179 \mathrm{HV}$, Tabela 4). Como discutido, um aumento no teor de $\mathrm{CO}_{2}$ no gás de proteção (mantendo uma mesma velocidade de alimentação do arame e polaridade do eletrodo) resulta em um aumento da energia de soldagem (Tabela 1) e, assim, em uma redução da velocidade de resfriamento das soldas. Um aumento no teor de $\mathrm{CO}_{2}$ (devido ao seu caráter oxidante) também altera a composição química do depósito devido às perdas por oxidação de elementos de liga e, assim, reduz a temperabilidade da zona fundida. Como consequiência, é de se esperar o aumento observado nos microconstituintes de mais alta temperatura de transformação (PG(G), PF(I) e FS(A) - provavelmente ferrita de placas laterais) e a redução dos microconstituintes de mais baixa temperatura de transformação (no caso FS(NA)), associado à redução na dureza da zona fundida. Da mesma forma, os grandes aumentos da diluição com o aumento do teor de $\mathrm{CO}_{2}$ no gás de proteção também podem resultar em variações na composição química da zona fundida e, assim, também contribuir para as alterações microestruturais e de dureza observadas. Acreditase que a grande variação da diluição resultante da soldagem com um único passe pode ter influenciado a microestrutura e a dureza de forma mais forte do que os demais fatores. Entretanto, na soldagem com vários passes, a variação da diluição com o aumento do teor de $\mathrm{CO}_{2}$ no gás de proteção deve ser bem menor.

\subsection{Efeito da Polaridade do Eletrodo}

Uma mudança da polaridade do eletrodo de positiva para negativa, para um mesmo tipo de gás de proteção e velocidade de alimentação do arame, resulta em reduções na corrente média de soldagem (variação máxima de 215 para 204 A) e em pequenos aumentos na tensão média do arco (variação máxima de 29,8 para 30,8 V, Figuras 3 e 4). Segundo Lancaster[18], é de se esperar na soldagem com eletrodos consumíveis maciços e polaridade negativa uma maior geração de calor na região do 
eletrodo, resultando (como observado também para o arame tubular rutílico) em uma redução da corrente necessária para fundir o arame em relação à soldagem com polaridade positiva. Espera-se também diferenças nos mecanismos responsáveis pela emissão a frio (não termiônica) de elétrons quando o cátodo é constituído pelo arame (polaridade do eletrodo negativa) ou pela peça a ser soldada (polaridade do eletrodo positiva). Estes mecanismos podem ser baseados principalmente na existência de camadas de óxidos na superfície do cátodo e, eventualmente, na formação de vapores metálicos em cátodos sem filme de óxidos [18,20]. Estas mudanças nos mecanismos de emissão a frio de elétrons podem resultar em alguma alteração no valor médio da tensão do arco, mesmo quando o comprimento do arco é mantido constante. De acordo com a Figura 4, percebe-se que uma mudança da polaridade do eletrodo de positiva para negativa na soldagem com $100 \% \mathrm{CO}_{2}$ (para uma mesma velocidade de alimentação do arame) resulta em uma menor flutuação nos valores de corrente de soldagem e de tensão do arco, indicando um aumento da estabilidade operacional do processo. Entretanto, a Figura 3 indica um comportamento inverso na soldagem com $75 \% \mathrm{Ar}-25 \% \mathrm{CO}_{2}$, ou seja, a operação com a polaridade negativa aumenta a flutuação dos valores de corrente e tensão indicando, assim, uma redução da estabilidade operacional. Portanto, a polaridade do eletrodo deve interferir de forma distinta nos parâmetros da transferência metálica do arame tubular rutílico dependendo do tipo de gás de proteção.

De acordo com a Tabela 1, nota-se que, para um mesmo tipo de gás de proteção e velocidade de alimentação do arame, uma mudança na polaridade do eletrodo de positiva para negativa resulta em alguma redução na eficiência de deposição, entretanto, esta redução é mais significativa na soldagem com $100 \% \mathrm{CO}_{2}$ (variação de 81 para $64 \%$ ). Pelas Figuras 5 e 6 também se percebe que a polaridade negativa, para um mesmo gás de proteção e velocidade de alimentação do arame, resulta em um aumento do nível de respingos em relação à soldagem com polaridade positiva. Esses efeitos são evidências da redução da estabilidade operacional quando se utiliza a polaridade do eletrodo negativa na soldagem com o arame tubular rutílico. Dessa forma, percebese que a observação isolada da flutuação nos valores de corrente de soldagem e tensão do arco não é suficiente para a avaliação da estabilidade operacional do processo quando se muda a polaridade do eletrodo de positiva para negativa na soldagem com $100 \% \mathrm{CO}_{2}$. Essa inconsistência pode ser entendida quando se percebe pela Figura 6 que na soldagem com $100 \% \mathrm{CO}_{2}$ (principalmente para a maior velocidade de alimentação do arame) apesar do aumento do nível de respingos na soldagem com polaridade negativa (indicando uma transferência mais repulsiva) o tamanho médio dos mesmos diminui. Isto sugere uma redução no tamanho médio das gotas metálicas, podendo resultar em menores variações no comprimento efetivo do arco com menores flutuações nos valores de corrente de soldagem e de tensão do arco.

A Tabela 2 e as macrografias das Figuras 5 e 6 indicam que uma mudança na polaridade do eletrodo de positiva para negativa afeta a geometria do cordão. De uma forma geral (à exceção da solda com $100 \% \mathrm{CO}_{2}$ e menor velocidade de alimentação), essa mudança resulta em reduções da largura (variação máxima de
11,3 para 10,1 mm), penetração máxima (variação máxima de 2,1 para 1,7 mm), área de penetração (variação máxima de 7,0 para 4,6 mm²) e diluição (variação máxima de 27,0 para 18,6 \%) e em um aumento do reforço (variação máxima de 2,5 para $2,9 \mathrm{~mm}$ ). A mudança para a polaridade negativa (para um mesmo do tipo de gás de proteção e velocidade de alimentação do arame) resultou em uma redução na corrente média de soldagem (variação máxima de 215 para 204 A, Figuras 3 e 4) e não implicou em maiores alterações na energia de soldagem (variação máxima de 0,88 para 0,84 kj/mm, Tabela 1). Entretanto, segundo Lancaster[18], é de se esperar na soldagem com eletrodos consumíveis maciços e polaridade negativa uma menor geração de calor na região da peça, o que também explicaria a tendência observada (para o arame tubular rutílico) de reduções na largura, penetração máxima e área de penetração. Em função da pequena variação da área depositada com a variação da polaridade (Tabela 2), a mudança para a polaridade negativa também tendeu a aumentar o reforço e a diminuir a diluição.

Observando-se as microestruturas das Figuras 5 e 6 e os resultados da metalografia quantitativa apresentados na Tabela 3 , percebe-se que a mudança na polaridade do eletrodo, para um mesmo do tipo de gás de proteção e velocidade de alimentação do arame, não afetou fortemente a microestrutura da zona fundida. Da mesma forma, a mudança na polaridade do eletrodo não alterou fortemente a dureza da zona fundida (variação máxima de 203 para 235 HV, Tabela 4). Como discutido, a mudança da polaridade positiva para a negativa tendeu a reduzir a diluição (variação máxima de 27,0 para 18,6 \%, Tabela 2) e, assim, deve resultar em alguma variação na composição química da zona fundida. Da mesma forma, apesar da energia de soldagem não ter variado significativamente com a polaridade (variação máxima 0,88 para $0,84 \mathrm{kj} / \mathrm{mm}$, Tabela 1 ), é de se esperar que ocorra alguma variação no rendimento térmico do processo com a mudança da polaridade resultando, assim, em alguma variação na velocidade de resfriamento das soldas. Os resultados indicam que estas eventuais variações na composição química e na velocidade de resfriamento com a mudança na polaridade do eletrodo não devem ter sido fortes o suficiente para resultar em maiores alterações microestruturais ou na dureza da zona fundida.

\subsection{Condições Operacionais Otimizadas}

Em princípio, deseja-se na soldagem de chapas grossas de aços estruturais com o arame tubular rutílico condições de boa estabilidade operacional e de maior produtividade (maior taxa de deposição). É desejável que essas condições sejam associadas a um cordão com boa aparência superficial, boa penetração e ausência de descontinuidades. Também se almeja uma microestrutura com predominância de microconstituintes capazes de favorecer a resistência mecânica, aliada a uma boa tenacidade e ductilidade da solda (por exemplo, com teores mais altos de ferrita acicular e mais baixos de ferrita primária de contorno de grão).

De acordo com as macrografias das Figuras 5 e 6, percebese que todas as condições operacionais avaliadas resultaram em cordões com aparentemente os mesmos níveis de porosidades e 
inclusões de escória e sem a presença de mordeduras. De acordo com a Tabela 1, as maiores taxas de deposição ocorreram na soldagem com a maior velocidade de alimentação do arame (principalmente com a polaridade do eletrodo positiva). As melhores estabilidades operacionais e que também resultaram em cordões com boa aparência superficial ocorreram na soldagem por $75 \% \mathrm{Ar}-25 \% \mathrm{CO}_{2}$ (principalmente com a polaridade do eletrodo positiva). De acordo com a Tabela 4 , as microestruturas com maior dureza (capazes de favorecer a resistência mecânica) ocorreram na soldagem com $75 \% \mathrm{Ar}-25 \% \mathrm{CO}_{2}$ (principalmente para menor velocidade de alimentação do arame). De acordo com a Tabela 3, o teor de ferrita acicular não variou apreciavelmente entre as condições avaliadas, entretanto, os menores teores de ferrita primária de contorno de grão ocorreram nas soldas com $75 \% \mathrm{Ar}-25 \% \mathrm{CO}_{2}$ (capazes de favorecer a tenacidade). Entretanto, de acordo com a Tabela 2, as maiores penetrações ocorreram na soldagem com $100 \% \mathrm{CO}_{2}$ (principalmente para a polaridade positiva).

Neste sentido, as condições de soldagem mais adequadas envolveriam a utilização da polaridade positiva e a maior velocidade de alimentação do arame $(9 \mathrm{~m} / \mathrm{min})$ com proteção por $100 \% \mathrm{CO}_{2}$ (caso a penetração seja um requisito essencial) ou por $75 \% \mathrm{Ar}-25 \% \mathrm{CO}_{2}$ (caso a estabilidade operacional, a aparência superficial do cordão e as propriedades mecânicas da solda sejam os requisitos principais).

\section{Conclusões}

Para as condições avaliadas na soldagem sobre chapa grossa de aço carbono comum de baixo teor de carbono (ABNT 1010) em posição plana com o arame tubular rutílico, variando-se isoladamente a composição do gás de proteção, a polaridade do eletrodo e a velocidade de alimentação do arame:

- Um aumento da velocidade de alimentação do arame (associada a um aumento proporcional na velocidade de soldagem) eleva os valores médios de corrente e tensão de soldagem e tende a reduzir a estabilidade operacional com proteção de $\mathrm{CO}_{2}$ puro (medida pelas oscilações de corrente e tensão, eficiência de deposição em polaridade negativa e nível de respingos em polaridade negativa) e aumentá-la com proteção de $75 \% \mathrm{Ar}-25 \% \mathrm{CO}_{2}$ (medida pelo nível de respingos em polaridade negativa e pelas oscilações de corrente e tensão). A velocidade do arame não pareceu afetar significativamente o nível de descontinuidades (porosidade, inclusões de escória e mordedura) nem a microestrutura do cordão, embora tenham sido observadas reduções na dureza da zona fundida (na soldagem com $75 \%$ Ar- $25 \% \mathrm{CO}_{2}$ ) e variações no formato do cordão.

- Um aumento do teor de $\mathrm{CO}_{2}$ no gás de proteção resulta em uma pequena variação no valor médio da corrente de soldagem e em um aumento no valor médio da tensão de soldagem e tende a reduzir a estabilidade operacional (medida pelas oscilações de corrente, eficiência de deposição principalmente em polaridade negativa e níveis de respingos e de irregularidades superficiais do cordão). $\mathrm{O}$ aumento do teor de $\mathrm{CO}_{2}$ resultou em variações no formato do cordão com formação de uma microestrutura mais grosseira e de menor dureza (com maiores teores de ferrita primária de contorno de grão) e com manutenção nos níveis de descontinuidades (porosidades, inclusões de escória e mordeduras).

- Uma mudança da polaridade do eletrodo de positiva para negativa resulta em uma redução no valor médio da corrente de soldagem e em um pequeno aumento no valor médio da tensão de soldagem e tende a aumentar a estabilidade operacional (medida pelas oscilações de corrente e tensão na soldagem com $\mathrm{CO}_{2}$ puro) ou reluzi-la (medida pelas oscilações de corrente e tensão na soldagem com $75 \% \mathrm{Ar}-25 \% \mathrm{CO}_{2}$, eficiência de deposição principalmente na soldagem com $\mathrm{CO}_{2}$ puro e nível de respingos). A mudança da polaridade não pareceu afetar significativamente o nível de descontinuidades (porosidades, inclusões de escória e mordeduras), a microestrutura e a dureza do cordão, entretanto, observou-se variações no formato do cordão.

- A observação isolada da flutuação nos valores de corrente de soldagem e tensão do arco demonstrou não ser suficiente para a avaliação da estabilidade operacional do processo quando se muda a polaridade do eletrodo de positiva para negativa na soldagem com $100 \% \mathrm{CO}_{2}$. Nesse caso, uma avaliação complementar envolveria a análise da eficiência de deposição e do nível e tamanho médio dos respingos.

- As condições de soldagem mais adequadas envolveriam a utilização da polaridade positiva e a maior velocidade de alimentação do arame $(9 \mathrm{~m} / \mathrm{min})$ com proteção por $100 \% \mathrm{CO}_{2}$ (para uma boa taxa de deposição, associada a uma boa penetração) ou por $75 \% \mathrm{Ar}-25 \% \mathrm{CO}_{2}$ (para uma boa taxa de deposição, associadas à adequadas estabilidade operacional, aparência superficial do cordão e propriedades mecânicas da solda).

\section{Agradecimentos}

Os autores agradecem a todos que contribuíram para a realização deste trabalho. Em particular à FAPEMIG pelo apoio financeiro (concessão de Bolsa de Iniciação Científica e financiamento via Projeto TEC-423/06).

\section{Referências Bibliográficas}

[1] MARQUES, P.V.; MODENESI, P.J.; BRACARENSE, A.Q. Soldagem Mig/Mag e com Arame Tubular. In: MARQUES, P.V.; MODENESI, P.J.; BRACARENSE, A.Q. Soldagem: Fundamentos e Tecnologia. 1a. ed., Belo Horizonte: UFMG, 2005. p.233-261.

[2] AMERICAN WELDING SOCIETY. Welding Process. In: AMERICAN WELDING SOCIETY. Welding Handbook, v.2, $8^{\text {th }}$ ed., Miami: AWS, 1991. p.158-190.

[3] STARLING, C.M.D.; MODENESI, P.J. Modelo Proposto para a Fusão de Arames Tubulares, Soldagem \& Inspeção, São Paulo, v. 12, n.3, p.168-178, 2007. 
[4] STARLING, C.M.D.; MODENESI, P.J. Avaliação da Transferência de Metal de Arames Tubulares, Soldagem \& Inspeção, São Paulo, v.11, n.3, p.147-155, 2006.

[5] STARLING, C.M.D.; MODENESI, P.J. Avaliação da Velocidade de Fusão do Arame na Soldagem FCAW com Eletrodo Negativo, Soldagem \& Inspeção, São Paulo, v.10, n.1, p.31-37, 2005.

[6] STARLING, C.M.D.; MODENESI, P.J. Efeito da Polaridade do Eletrodo na Velocidade de Fusão de Arames Tubulares, Soldagem \& Inspeção, São Paulo, v.10, n.3, p.101-108, 2005.

[7] STARLING, C.M.D. et al. Avaliação da Velocidade de Fusão de Arames Tubulares, Soldagem \& Inspeção, São Paulo, v.9, n.1, p.31-37, 2004.

[8] OLIVEIRA, J.E.M.; BRACARENSE, A.Q. Estudo da Morfologia do Cordão de Solda Obtido com o Processo Arame Tubular em Diferentes Posições de Soldagem. In: CONGRESSO NACIONAL DE SOLDAGEM, 29, 2003, São Paulo. Anais... São Paulo: Associação Brasileira de Soldagem, 2003, 12p.

[9] ARAÚJO, W.R. Comparação entre a Soldagem Robotizada com Arame Sólido e "Metal Cored" - A ocorrência do "Finger": 2004. 79p. Dissertação (Mestrado) - Curso de Pós-Graduação em Eng. Mecânica, Escola de Engenharia da Universidade Federal de Minas Gerais, Belo Horizonte.

[10] BRAGA, E.M.; MOTA, C.A.M.; FARIAS, J.P. Uma Contribuição ao Estudo da Soldagem a Arame Tubular Autoprotegido em Corrente Pulsada. In: ENCONTRO NACIONAL DE TECNOLOGIA DA SOLDAGEM, 24, 1998, Fortaleza. Anais... São Paulo: Associação Brasileira de Soldagem, 1998. 10p.

[11] BLACKMAN, S. et al. Pulsed MIG Welding with GásShielded Flux Cored Wires - MIG Synergic Update, Welding \& Metal Fabrication - Special Supplement, p.12-14, april 1998.

[12] SVOBODA, H. et al. Efecto de los Parámetros de Soldadura sobre las Propiedades de los Depósitos Ferríticos Aleados al C-Mn-Ni Obtenidos con Alambres Tubulares de Relleno Rutílico y Metálico. In: CONGRESSO NACIONAL DE SOLDAGEM, 29, 2003, São Paulo. Anais... São Paulo: Associação Brasileira de Soldagem, 2003. 12p.

[13] VENTRELLA, V.A. Microestrutura e Tenacidade do Aço API 5LX - Grau 70 Soldado com Arame Tubular AWS E-81T1Ni1 e Eletrodo Revestido AWS E-8010-G. In: CONGRESSO BRASILEIRO DE ENGENHARIA E CIÊNCIA DOS MATERIAIS, 26, 2004, Porto Alegre. Anais... Porto Alegre: Associação Brasileira de Ciências Mecânicas, 2004. 15p.

[14] SANTOS NETO, N.F.; TREVISAN, R.E. Caracterização de Juntas de Aço API 5L X-70 Soldadas pelo Processo de Soldagem a Arco com Arame Tubular Autoprotegido. In: CONGRESSO NACIONAL DE SOLDAGEM, 30, 2004, Rio de Janeiro. Anais... São Paulo: Associação Brasileira de Soldagem, 2004. 8p.

[15] FALS, H.C.; TREVISAN, R.E. Características do Trincamento Assistido pelo Hidrogênio de um Aço Microligado Soldado pelo Processo FCAW. In: ENCONTRO NACIONAL DE TECNOLOGIA DA SOLDAGEM, 24, 1998, Fortaleza. Anais... São Paulo: Associação Brasileira de Soldagem, 1998. $10 \mathrm{p}$.

[16] INTERNATIONAL INSTITUTE OF WELDING. IIW Doc. n. IX-1533-88; Guide to the Light Microscope Examination of Ferritic Steel Weld Metals. 1988. 20p.

[17] AMERICAN SOCIETY FOR TESTING AND MATERIALS, Philadelphia. ASTM E562-89; Standard Test Method for Determining Volume Fraction by Systematic Manual Point Count. Philadelphia, 1989. Annual Book of ASTM Standards, p. 502-507.

[18] LANCASTER, J.F. The Physics of Welding. 2.ed. Pergamon Press \& International Institute of Welding, 1986. 340p.

[19] TUSEK, J.; SUBAN, M. Experimental research of the effect of hydrogen in argon as a shielding gas in arc welding of highalloy stainless steel, International Journal of Hydrogen Energy, Slovenia, v.25, n.25, p.369-376, 2000.

[20] GUILE, A.E.; JUTTNER, B. Basic erosion processes of oxidized and clean metal cathodes by eletric arcs, IEEE trans. Plasma Sci, n.8 p.259-69, sept. 1980. 